\title{
Het effect van het inkorten en vereenvoudigen van een gezondheidsvragenlijst op de respons
}

\section{Een pilot in drie GGD-regio's}

\author{
Claudia Verhagen · Henriëtte Dijkshoorn · Camiel Wijffels · Johan Werkhoven · Caroline Dekkers · \\ Antoine Meijerman · Suzan van Dijken · Gerben Huijgen
}

Published online: 17 November 2020

(C) The Author(s) 2020

\begin{abstract}
Samenvatting GGD'en brengen vierjaarlijks de gezondheidssituatie van de volwassen bevolking in beeld via een gezondheidsvragenlijst. Een dalende respons, vooral onder jongvolwassenen en mannen, zet de representativiteit van onderzoeksresultaten onder druk. De GGD'en van Amsterdam, Flevoland en Haaglanden, en I\&O Research onderzochten in twee onderzoeksvarianten de effecten van het inkorten en vereenvoudigen van de gezondheidsvragenlijst op de respons. Variant 1: in Amsterdam en Almere ontving een steekproef van 3.000 inwoners van 19- tot en met 64-jarigen een (standaard) 'lange' of 'korte' gezondheidsvragenlijst (respectievelijk 20 en 12 pagina's). Variant 2: in Den Haag ontvingen 4.500 inwoners van 19- tot en met 64-jarigen in achterstandswijken een (standaard) 'lange' gezondheidsvragenlijst of 'zeer korte' themavragenlijst over psychosociale gezondheid of dezelfde 'zeer korte' themavragenlijst op B1taalniveau (respectievelijk 20, 6 en 6 pagina's). In Amsterdam en Almere verschilden de respons en de gezondheidsuitkomsten op de lange en korte vragenlijst niet. In Haagse achterstandswijken was de respons op beide zeer korte themavragenlijsten hoger dan op de lange vragenlijst. Toepassing van B1-
\end{abstract}

C. Verhagen $(\bowtie) \cdot$ H. Dijkshoorn · C. Wijffels · J. Werkhoven afdeling Epidemiologie, Gezondheidsbevordering en Zorginnovatie, GGD Amsterdam, Amsterdam, Nederland cverhagen@ggd.amsterdam.nl

C. Dekkers · A. Meijerman

afdeling Epidemiologie en Gezondheidsbevordering, GGD Haaglanden, Den Haag, Nederland

S. van Dijken

afdeling Beleid en Onderzoek, GGD Flevoland, Lelystad, Nederland

G. Huijgen

I\&O Research BV, Amsterdam/Enschede, Nederland taalniveau bevorderde de respons niet. Haagse respondenten rapporteerden op de B1-themavragenlijst wel vaker een verhoogd risico op psychische klachten dan op de lange vragenlijst. Dit onderzoek laat zien dat het gebruik van een zeer korte thematische gezondheidsvragenlijst in achterstandswijken een positief responseffect kan hebben.

Trefwoorden gezondheidsvragenlijst · GGD · respons

The response effect of shortening and simplifying of a health questionnaire A pilot by three Municipal Health Services

Abstract The Dutch health monitor consists of quadrennial questionnaires by the Municipal Health Services (GGD) aimed at assessing the health status of the population. This monitor faces a decreasing response rate, particularly among young adults and men, which might impair the representativeness of the results. In 2018, the GGD in Amsterdam, The Hague and Almere and I\&O Research studied in two variants whether changing the questionnaire improves the response rate. Variant 1: in Amsterdam and Almere, 3,000 19to 64-year-olds received a comprehensive or shortened questionnaire (20 vs. 12 pages). Variant 2: 4,500 19- to 64-year-olds in deprived neighbourhoods in The Hague received a comprehensive questionnaire, a very short questionnaire on mental health or this very short questionnaire at language level B1 (respectively 20, 6 and 6 pages). In Amsterdam and Almere, the response rate and results did not differ between the comprehensive and the shortened questionnaire. In the deprived neighbourhoods of The Hague, both very short questionnaires yielded higher response rates than the comprehensive questionnaire. Using B1-level questionnaires did not improve the response rate, but respondents were more likely 
to report psychosocial complaints. This study shows that, in deprived neighbourhoods, a very short health questionnaire could improve the response rate.

Keywords Health questionnaire - Municipal Health Services $\cdot$ Response rate

\section{Inleiding}

Gemeenten hebben de wettelijke taak de gezondheidssituatie van hun inwoners, op landelijk uniforme wijze, te monitoren [1]. Hiertoe voeren alle GGD'en in Nederland, in samenwerking met het Rijksinstituut voor Volksgezondheid en Milieu (RIVM) en het Centraal Bureau voor de Statistiek (CBS), elke vier jaar een Gezondheidsmonitor (GM) volwassenen en ouderen uit onder inwoners van 19 jaar en ouder. Resultaten van de GM worden gebruikt als input voor het lokale gezondheidsbeleid.

GGD'en zien de respons op de GM de laatste jaren afnemen. Landelijk daalde de gemiddelde respons onder inwoners van 19 jaar en ouder van $47 \%$ in 2012 naar $41 \%$ in 2016 [2, 3]. Vooral de respons onder 19- tot en met 64 -jarigen daalt; variërend van $33 \%$ tot $50 \%$ in 2012 tussen GGD-regio's [2], naar een landelijk gemiddelde van $33 \%$ in 2016 [3, 4]. Daarnaast is er sprake van een selectieve respons: jonge mannen (19 tot en met 34 jaar) en inwoners met een niet-westerse migratieachtergrond responderen doorgaans minder goed [2-5]. Een selectieve non-respons zet de representativiteit van de resultaten van de GM onder druk.

Er zijn diverse internationale onderzoeken uitgevoerd naar het verhogen van de respons bij vragenlijstonderzoek, zowel op papier [6-13], als online [6, 14-20]. In deze onderzoeken werd onder andere gekeken naar de invloed van het personifiëren van de uitnodiging $[9,12,13]$, het onderwerp en de moeilijkheid van de vragenlijst $[7,9,16,19]$, incentives $[6,9$, $10,13]$, het vermelden van de verwachte duur van het invullen van de vragenlijst [12, 15, 17] en de lengte van de vragenlijst op de respons $[6-9,11-13,17,19$, 20]. Vier onderzoeken waren gericht op het verhogen van de respons in gezondheidsonderzoek [6, 9, 11, 13]. Resultaten lieten zien dat een ingekorte vragenlijst en een (vooraf meegestuurde) incentive een positief effect hadden op de respons [6, 9, 11, 13]. Daarnaast was de respons hoger wanneer de vragen over een interessanter onderwerp gingen en de uitnodiging gepersonifieerd was $[6,7,9-13,16-20]$. De laatste jaren worden smartphones steeds vaker gebruikt bij online surveyonderzoek [21]. Gebruiksvriendelijkheid en een korte invulduur van de vragenlijst bevorderen hierbij de respons [22, 23].

De standaardvragenlijsten die GGD'en in de GM op papier en online aanbieden aan respondenten, bestaan uit een uitgebreide basisvragenlijst waaraan GGD'en lokale vragen toevoegen. Gezien de gunstige effecten van een kortere vragenlijst op de respons in vragenlijstonderzoek, is het van belang om het effect van het inkorten van de standaardvragenlijst op de respons van de GM te onderzoeken. Het aantal Nederlandse onderzoeken naar het effect van een kortere vragenlijst op de respons in vragenlijstonderzoek is tot op heden beperkt [13].

Ook het vereenvoudigen van het taalniveau van vragenlijsten en uitnodigingsbrieven van de GM kan de respons gunstig beïnvloeden. In de GM worden overwegend (internationaal) gevalideerde vragen gebruikt die voor laaggeletterden wellicht niet altijd begrijpelijk zijn vanwege het taalniveau. In het algemeen wordt B1-taalniveau geadviseerd voor teksten [24, 25]. Vooralsnog zijn GGD'en terughoudend in het aanpassen van vragen uit de GM naar een eenvoudiger B1-taalniveau vanwege het belang van het volgen van trends en de invloed op de validiteit van de vragen. Voor zover wij weten is het effect van eenvoudiger taalgebruik op de respons in vragenlijstonderzoek in Nederland nog weinig onderzocht. Eén onderzoek laat zien dat het vereenvoudigen van het taalniveau van een uitnodigingstekst voor een online panel geen effect heeft op de respons [26].

In Amsterdam, Almere en Den Haag is een vragenlijstonderzoek uitgevoerd onder een steekproef van inwoners van 19 tot en met 64 jaar. In Amsterdam en Almere is onderzocht welke invloed het inkorten van de gezondheidsvragenlijst van 20 naar 12 pagina's heeft op de respons. In Den Haag is in achterstandswijken onderzocht of het zeer sterk inkorten van de gezondheidsvragenlijst van 20 naar 6 pagina's, alsook het vereenvoudigen van het taalgebruik responsbevorderend werkt. We onderzoeken de responsverschillen tussen subgroepen naar leeftijd, geslacht en herkomst, en de gezondheidsuitkomsten. De resultaten van dit onderzoek kunnen een waardevolle bijdrage leveren aan de uitvoering van toekomstige landelijke gezondheidsmonitors, en aan andere (gezondheids)surveys.

\section{Methode}

\section{Steekproef}

Dit onderzoek, met twee varianten, is uitgevoerd van september tot november 2018. Onderzoeksvariant 1: in Amsterdam en Almere zijn een lange en een korte gezondheidsvragenlijst uitgezet onder een steekproef van elk 1.500 inwoners. Onderzoeksvariant 2: in Den Haag zijn een lange gezondheidsvragenlijst, een zeer korte themavragenlijst en een zeer korte themavragenlijst op B1-taalniveau uitgezet onder een steekproef van elk 1.500 inwoners. De steekproef werd getrokken uit de Basisregistratie Personen (BRP). De inclusiecriteria waren: 1) leeftijd 19 tot en met 64 jaar (op 1 september 2018), 2) niet woonachtig in een verzorgings- en/of verpleeghuis, 3) alleen voor Den Haag: woonachtig in een van de Haagse wijken met achterstand (in 2016 betrof dat de volgende wijken: Regentessekwartier, Stations- 
Tabel 1 Opzet van het vragenlijstonderzoek

\begin{tabular}{|c|c|c|c|c|c|c|c|}
\hline \multirow[b]{2}{*}{ Type vragenlijst } & \multicolumn{2}{|c|}{ Amsterdam } & \multicolumn{2}{|l|}{ Almere } & \multicolumn{3}{|c|}{ Den Haag ${ }^{a}$} \\
\hline & lang & kort & lang & kort & lang & thema & thema-B1 \\
\hline Aantal pagina's & 20 & 12 & 20 & 12 & 20 & 6 & 6 \\
\hline Aantal pagina's met vragen & 17 & 9 & 17 & 9 & 17 & 3 & 4 \\
\hline Aantal vragen ${ }^{b}$ & 171 & 96 & 171 & 96 & 171 & 31 & 31 \\
\hline \multirow[t]{2}{*}{ Verwachte invulduur (minuten) } & 30 & 10 à 15 & 30 & 10 à 15 & 30 & 5 à 10 & 5 à 10 \\
\hline & $n$ & $n$ & $n$ & $n$ & $n$ & $n$ & $n$ \\
\hline Totaal aantal in steekproef & 1.500 & 1.500 & 1.500 & 1.500 & 1.500 & 1.500 & 1.500 \\
\hline \multicolumn{8}{|c|}{ Verstuurde vragenlijsten naar leeftijd } \\
\hline 19-24 jaar & 0 & 430 & 141 & 116 & 212 & 202 & 194 \\
\hline 25-29 jaar & 392 & 156 & 164 & 161 & 199 & 208 & 211 \\
\hline 30-34 jaar & 351 & 164 & 156 & 175 & 181 & 208 & 197 \\
\hline 35-44 jaar & 290 & 271 & 301 & 374 & 325 & 343 & 337 \\
\hline 45-54 jaar & 249 & 254 & 402 & 364 & 328 & 276 & 286 \\
\hline 55-64 jaar & 206 & 225 & 328 & 299 & 238 & 243 & 266 \\
\hline Totaal & 1.488 & 1.482 & 1.492 & 1.489 & 1.483 & 1.480 & 1.491 \\
\hline Fout geadresseerd/retourpost & 12 & 29 & 8 & 11 & 17 & 19 & 9 \\
\hline
\end{tabular}

buurt, Schildersbuurt, Transvaalkwartier, Bouwlust en Vrederust, Morgenstond, Moerwijk, Groente- en Fruitmarkt, Laakkwartier en Spoorwijk [27]). Den Haag heeft voor deze groep inwoners gekozen omdat de respons onder inwoners met een niet-westerse migratieachtergrond over het algemeen laag is en deze groep vooral woont in wijken met achterstand. Het steekproefbestand bevatte geboortedatum, geslacht, naw-gegevens (naam, adres, woonplaats) en geboorteland van de persoon en diens vader en moeder (ter bepaling van de herkomst). In Den Haag waren gegevens over herkomst niet beschikbaar vanwege regulering binnen het Haagse Basisregistratie Personen (BRP). De leeftijdsverdeling van de steekproef naar zes leeftijdscategorieën en naar vragenlijstvariant staat in tab. 1. In Almere en Den Haag bevatte de steekproef naar verhouding meer inwoners van 35 jaar en ouder. In Amsterdam zijn abusievelijk geen 19- tot en met 24-jarigen in de steekproef voor de lange vragenlijst geïncludeerd. De verdeling in de steekproef naar herkomst was in Amsterdam: 46,0\% Nederlands, 18,4\% overig westers en $35,6 \%$ niet-westers. Voor Almere was dat: $59,3 \%$ Nederlands, $10,3 \%$ overig westers en $38,4 \%$ niet-westers.

\section{Onderzoeksopzet}

Personen in de steekproef kregen een uitnodigingsbrief thuisgestuurd. De brief bevatte een persoonlijke inlogcode waarmee de persoon kon inloggen op een website om de vragenlijst in te vullen met een computer, tablet of smartphone. De online vragenlijst was ook in het Engels beschikbaar; dit werd vermeld in de brief. Er werden twee reminders verstuurd, drie en zes weken na de uitnodigingsbrief. Bij de eerste reminder werd een papieren vragenlijst meegestuurd.
Respondenten konden na het invullen van de online vragenlijst een persoonlijk gezondheidsadvies ontvangen, gebaseerd op de eigen antwoorden. Onder de deelnemers in Den Haag en Amsterdam werden vier cadeaubonnen verloot; in Almere kreeg elke 15e deelnemer een cadeaubon van 10 euro.

GGD Amsterdam, GGD Flevoland en GGD Haaglanden hebben dit onderzoek uitgevoerd in samenwerking met I\&O Research bv. I\&O Research verzorgde de verzending van de uitnodigingsbrieven, reminders en vragenlijsten, hield de respons bij, verzorgde de hosting van de online vragenlijst, scande de papieren vragenlijsten en maakte onderzoeks- en responsbestanden. De uitwisseling van databestanden tussen I\&O Research en de GGD'en verliep via een beveiligde server.

\section{Vragenlijsten}

Tabel 1 laat zien welke vragenlijstvariant (lang, kort, thema en thema-B1) in de drie steden is uitgezet. Als basis werd de vragenlijst van de GM 2016 van GGD Amsterdam gebruikt. Deze 'lange' vragenlijst omvatte 20 pagina's en werd in elke stad uitgezet in een steekproef van 1.500 inwoners van 19 tot en met 64 jaar. Deze vragenlijst bevatte 171 vragen over lichamelijke en psychosociale gezondheid, participatie, leefstijl, leefomgeving en achtergrondkenmerken. Een 'korte' vragenlijst van 12 pagina's (96 vragen) betrof onderwerpen die in 2016 onderdeel waren van de landelijke basisvragenset, aangevuld met twee lokale thema's uit de GM 2016 van Amsterdam (drugsgebruik en gedragsintenties). In Amsterdam en Almere werd deze korte vragenlijst uitgezet in een steekproef van 1.500 inwoners. In Den Haag werd naast de lange vragenlijst een 'zeer korte' themavragenlijst uitgezet en dezelfde 
Tabel 2 Verschillen in responspercentages tussen typen vragenlijsten per stad uitgedrukt als oddsratio (OR; 95\%betrouwbaarheidsinterval) (lange vragenlijst $=$ referentie)

\begin{tabular}{|c|c|c|c|c|}
\hline Stad & Vragenlijst (aantal in steekproef) & Respons (\%) & OR (95\%-BI) & OR $(95 \%-B I)^{b}$ \\
\hline \multirow[t]{2}{*}{ Amsterdam $^{\mathrm{a}}$} & lang $(n=1.488)$ & 20,4 & ref & ref \\
\hline & kort $(n=1.051)$ & 24,3 & $1,25(1,03-1,51)^{\star}$ & $1,13(0,93-1,37)$ \\
\hline \multirow[t]{2}{*}{ Almere $^{\mathrm{a}}$} & lang $(n=1.492)$ & 21,8 & ref & ref \\
\hline & kort $(n=1.489)$ & 21,7 & $1,00(0,84-1,18)$ & $1,03(0,86-1,24)$ \\
\hline \multirow[t]{3}{*}{ Den Haaga,c } & lang $(n=1.483)$ & 14,7 & ref & ref \\
\hline & thema $(n=1.480)$ & 19,0 & $1,36(1,12-1,65)^{\star}$ & $1,38(1,14-1,68)^{\star}$ \\
\hline & thema-B1 $(n=1.491)$ & 20,4 & $1,49(1,23-1,80)^{\star}$ & $1,48(1,22-1,80)^{\star}$ \\
\hline
\end{tabular}

'zeer korte' themavragenlijst op B1-taalniveau, elk in een steekproef van 1.500 inwoners woonachtig in wijken met achterstand. Deze themavragenlijsten telden 6 pagina's (31 vragen) en bevatten alleen vragen over psychosociale problematiek (eenzaamheid, het risico op een depressie en/of angststoornis en stress), ervaren gezondheid en achtergrondkenmerken. Voor het omzetten van de tekst naar B1-taalniveau is gebruikgemaakt van verschillende websites [11-13]. De uitnodigingsbrief voor alle deelnemers was ook geschreven op B1-taalniveau. Hierin werden geschatte invultijden vermeld voor de lange, de korte of de themavragenlijsten, respectievelijk, ongeveer een half uur, 10 à 15 minuten en 5 à 10 minuten. De online vragenlijsten konden ook in het Engels worden ingevuld, met uitzondering van de B1-themavragenlijst.

\section{Statistische analyse}

Descriptieve statistiek is gebruikt om per vragenlijstvariant de responspercentages naar leeftijd, geslacht, herkomst, invulmodus (papier, computer, tablet, smartphone) en invulduur te analyseren. Verschillen tussen de vragenlijstvarianten werden getoetst met een chi-kwadraattoets en de kruskall-wallistoets. De invulduur was alleen bekend voor respondenten die de online vragenlijst hadden ingevuld. Een invulduur langer dan 90 minuten werd niet meegenomen, omdat dit waarschijnlijk respondenten betrof die het invullen hadden onderbroken. Het effect van het type vragenlijst op de respons is per stad onderzocht door middel van multivariabele logistische regressieanalyse, waarbij gecorrigeerd werd voor leeftijd en geslacht. Tevens werd met deze regressietechniek onderzocht of het type vragenlijst invloed had op drie dichotome gezondheidsuitkomsten: ervaren gezondheid (minder dan goed/(zeer) goed); eenzaamheid (score op eenzaamheidsschaal $\geq 9 /<9$ ) en risico op een depressie en/of angststoornis (K10score $\geq 30 /<30$ ) $[28-30]$. $P$-waarden $<0,05$ werden beschouwd als statistisch significant. Alle analyses werden uitgevoerd met het statistische analyseprogramma SPSS, versie 21. Voor Amsterdam werden alleen 25- tot en met 64-jarigen in de analyses meegenomen, omdat er abusievelijk geen 19- tot en met 24 -jarigen in de steekproef voor de lange vragenlijst waren opgenomen.

\section{Resultaten}

\section{Respons naar type vragenlijst}

Tabel 2 laat de responspercentages voor Amsterdam, Almere en Den Haag zien, uitgesplitst naar type vragenlijst. De respons op de lange vragenlijst in Amsterdam $(20,4 \%)$ was lager dan die op de korte vragenlijst $(24,3 \%)$. Dit verschil was na correctie voor leeftijd en geslacht niet meer significant (gecorrigeerde $\mathrm{OR}=1,13,95 \%$-BI: 0,93-1,37). In Almere verschilde de respons tussen de lange $(21,8 \%)$ en de korte $(21,7 \%)$ vragenlijst niet. In de achterstandswijken in Den Haag was de respons op de themavragenlijst (19,0\%) en op de B1-themavragenlijst $(20,4 \%)$ hoger dan op de lange vragenlijst $(14,7 \%)$. Dit verschil bleef significant na correctie voor leeftijd en geslacht (OR thema $=1,38,95 \%$-BI: $1,14-1,68$, OR thema-B1 $=1,48$, $95 \%-\mathrm{BI}: 1,22-1,80)$. De respons op beide themavragenlijsten verschilde onderling niet.

De respons op de lange vragenlijst onder 25-64 jarigen in Amsterdam en Almere was hoger dan die in achterstandswijken in Den Haag (gecorrigeerde OR voor leeftijd en geslacht respectievelijk 1,50, $95 \%-\mathrm{BI}$ : 1,23-1,83 en 1,57, $95 \%$-BI: $1,28-1,92$ ).

\section{Respons naar achtergrondkenmerken}

Tabel 3 toont voor elke stad de respons op de lange, korte en themavragenlijsten, uitgesplitst naar achtergrondkenmerken. In Amsterdam respondeerden inwoners van Nederlandse herkomst vaker op de korte dan op de lange vragenlijst. In Den Haag respondeerden 19- tot en met 24-jarigen vaker op de B1-themavragenlijst dan op de reguliere themavragenlijst en de lange vragenlijst. Bij mannen zien we dit ook, maar is het verschil in respons tussen de reguliere themavragenlijst en de B1-themavragenlijst niet significant. 
Tabel 3 Responspercentages in Amsterdam, Almere en Den Haag op de lange, korte en themavragenlijst naar achtergrondkenmerken

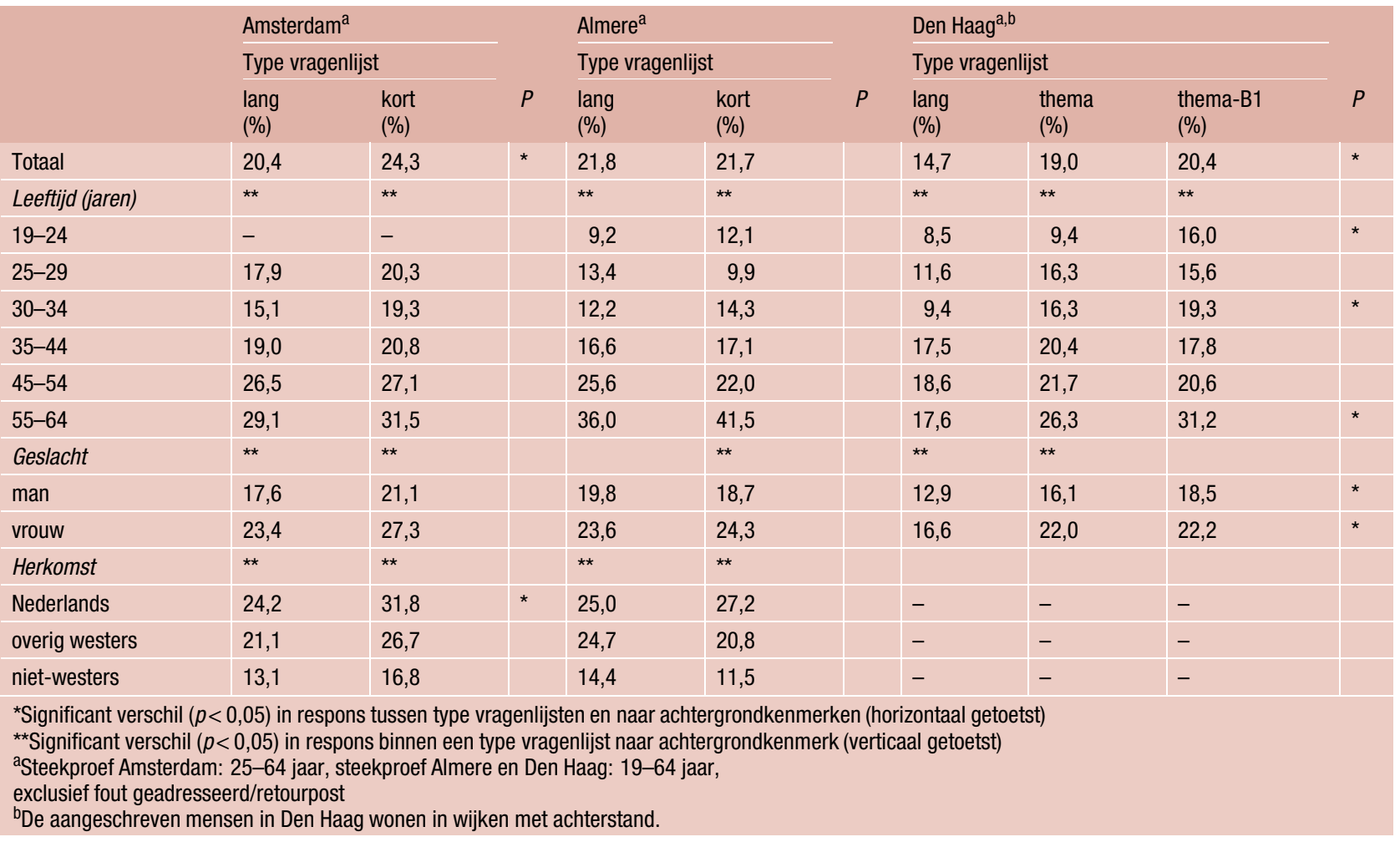

Vrouwen, 30- tot en met 34-jarigen en 55- tot en met 64-jarigen respondeerden vaker op beide themavragenlijsten dan op de lange vragenlijst. In Almere was er geen verschil in achtergrondkenmerken tussen respondenten op de lange en de korte vragenlijst. Voor alle typen vragenlijsten gold dat 45-plussers een hogere respons hadden en over het algemeen respondeerden vrouwen vaker dan mannen. Ook herkomst speelt een rol: inwoners van Nederlandse herkomst deden het vaakst mee, gevolgd door inwoners van overige westerse herkomst. Inwoners van niet-westerse herkomst vulden de vragenlijst het minst vaak in.

\section{Wijze van deelname}

In alle steden vulden twee op de drie respondenten de vragenlijst online in via pc, tablet of smartphone; een derde deed mee op papier (zie tab. 4). Binnen elke stad speelde de lengte van de vragenlijst geen rol bij de manier van deelname. In de Haagse achterstandswijken was er een relatief hoog gebruik van de smartphone. Een op de zes respondenten in Den Haag heeft online de lange vragenlijst niet afgemaakt (18,1\%). In Amsterdam respondeerde een op de acht deelnemers op de korte vragenlijst met een Engelse vragenlijst.

\section{Effect van het type vragenlijst op gezondheidsuitkomsten}

Tabel 5 toont per stad de resultaten van de multivariabele regressieanalyse, waarbij gekeken is naar de invloed van het type vragenlijst op drie gezondheidsindicatoren (ervaren gezondheid, eenzaamheid en risico op een depressie en/of angststoornis). Na correctie voor achtergrondkenmerken waren er in Amsterdam en Almere geen significante verschillen in gezondheidsuitkomsten tussen respondenten op de lange of korte vragenlijst. In Den Haag waren er geen verschillen tussen respondenten op de lange vragenlijst en de themavragenlijst. Haagse respondenten die de B1themavragenlijst invulden, rapporteerden echter vaker een hoger risico op een depressie en/of angststoornis dan respondenten die de lange vragenlijst invulden (OR=1,72, $95 \%$-BI: 1,03-2,86).

\section{Beschouwing}

GGD'en zien de respons op de GM volwassenen en ouderen dalen. Met dit onderzoek keken we in drie gemeenten of het inkorten van de gezondheidsvragenlijst en het vereenvoudigen van het taalniveau de respons bevordert. In Amsterdam en Almere had het inkorten van de gezondheidsvragenlijst van 20 naar 12 pagina's geen effect op de respons en evenmin op de gezondheidsuitkomsten. In achterstandswijken van Den Haag was de respons op een themavragen- 
Tabel 4 Invulmodus (\%), deelnemers Engelse vragenlijst (\%), online vragenlijst niet afgemaakt (\%) en invulduur (mediaan in minuten) naar type vragenlijst in de drie steden

\begin{tabular}{|c|c|c|c|c|c|c|c|c|c|c|}
\hline & \multicolumn{2}{|c|}{ Amsterdam $^{\mathrm{a}}$} & \multirow[b]{3}{*}{$P$} & \multirow{2}{*}{\multicolumn{2}{|c|}{$\frac{\text { Almere }^{\mathrm{a}}}{\text { Type vragenlijst }}$}} & \multirow[b]{3}{*}{$P$} & \multicolumn{3}{|c|}{ Den Haag ${ }^{\mathrm{a}, \mathrm{c}}$} & \multirow[b]{3}{*}{$P$} \\
\hline & \multicolumn{2}{|c|}{ Type vragenlijst } & & & & & \multicolumn{3}{|c|}{ Type vragenlijst } & \\
\hline & $\begin{array}{l}\text { lang } \\
n=304\end{array}$ & $\begin{array}{l}\text { kort } \\
n=255\end{array}$ & & $\begin{array}{l}\text { lang } \\
n=325\end{array}$ & $\begin{array}{l}\text { kort } \\
n=323\end{array}$ & & $\begin{array}{l}\text { lang } \\
n=218\end{array}$ & $\begin{array}{l}\text { thema } \\
n=281\end{array}$ & $\begin{array}{l}\text { thema-B1 } \\
n=304\end{array}$ & \\
\hline \multicolumn{11}{|l|}{ Invulmodus } \\
\hline papier (\%) & 34,2 & 34,5 & & 34,8 & 33,1 & & 36,9 & 32,7 & 31,9 & \\
\hline \multicolumn{11}{|l|}{ online (\%) } \\
\hline $\mathrm{pc}$ & 46,1 & 46,7 & & 41,5 & 39,9 & & 38,7 & 38,4 & 38,2 & \\
\hline tablet & 7,6 & 9,8 & & 11,7 & 14,6 & & 6,9 & 5,0 & 4,0 & \\
\hline smartphone & 12,2 & 9,0 & & 12,0 & 12,4 & & 17,5 & 23,8 & 25,9 & \\
\hline Totaal (\%) & 100 & 100 & & 100 & 100 & & 100 & 100 & 100 & \\
\hline \multirow[t]{2}{*}{ Engelse versie (\%) } & 1,9 & 16,4 & * & 1,2 & 2,2 & & 6,0 & 4,6 & $n v t^{d}$ & \\
\hline & $n=200$ & $n=167$ & & $n=212$ & $n=216$ & & $n=138$ & $n=189$ & $n=208$ & \\
\hline $\begin{array}{l}\text { Online vragenlijst niet afge- } \\
\text { maakt (\%) }\end{array}$ & 8,0 & 7,8 & & 9,0 & 7,9 & & 18,1 & 6,3 & 3,4 & * \\
\hline $\begin{array}{l}\text { Invulduur }{ }^{b} \text { (mediaan in minu- } \\
\text { ten) }\end{array}$ & 22 & 17 & * & 23 & 16 & * & 26 & 7 & 7 & * \\
\hline
\end{tabular}

Tabel 5 Verschillen in gezondheidsuitkomsten in de drie steden naar type vragenlijst (\% en oddsratio's)

\begin{tabular}{|c|c|c|c|c|c|c|}
\hline \multirow[b]{2}{*}{ Type vragenlijst } & \multicolumn{2}{|c|}{ Ervaren gezondheid minder dan goed } & \multicolumn{2}{|c|}{ Ernstig eenzaam } & \multicolumn{2}{|c|}{ Hoog risico op een depressie en/of angststoornis } \\
\hline & $\%$ & OR $(95 \%-B I)^{\mathrm{a}}$ & $\%$ & $\mathrm{OR}(95 \%-\mathrm{BI})^{\mathrm{a}}$ & $\%$ & $\mathrm{OR}(95 \%-\mathrm{Bl})^{\mathrm{a}}$ \\
\hline \multicolumn{7}{|l|}{ Amsterdam } \\
\hline lang $(n=304)$ & 19,1 & Ref & 11,5 & ref & 8,4 & ref \\
\hline $\operatorname{kort}(n=255)$ & 19,6 & $1,30(0,80-2,13)$ & 16,7 & $1,28(0,74-2,21)$ & 7,7 & $0,86(0,43-1,72)$ \\
\hline \multicolumn{7}{|l|}{ Almere } \\
\hline lang $(n=325)$ & 22,8 & Ref & 12,6 & ref & 7,8 & ref \\
\hline $\operatorname{kort}(n=323)$ & 27,2 & $0,72(0,49-1,06)$ & 9,8 & $0,81(0,48-1,36)$ & 5,4 & $0,76(0,40-1,48)$ \\
\hline \multicolumn{7}{|l|}{ Den Haag ${ }^{b}$} \\
\hline lang $(n=217)$ & 32,3 & Ref & 17,4 & ref & 14,6 & ref \\
\hline thema $(n=281)$ & 36,3 & $0,83(0,55-1,26)$ & 18,7 & $1,16(0,71-1,90)$ & 15,8 & $1,21(0,71-2,07)$ \\
\hline thema-B1 $(n=302)$ & 41,7 & $0,68(0,45-1,01)$ & 21,2 & $1,34(0,83-2,16)$ & 21,0 & $1,72(1,03-2,86)^{\star}$ \\
\hline
\end{tabular}

lijst van 6 pagina's over psychosociale gezondheid, al dan niet op B1-taalniveau, hoger dan op de lange vragenlijst. Het gebruik van de themavragenlijst op B1taalniveau werkt niet extra responsbevorderend, maar liet wel een effect zien op de uitkomsten.

Het gunstige effect van het inkorten van de vragenlijst op de respons die we zien in nationale en internationale onderzoeken [6-9, 11-14, 17, 19, 20], vinden we in ons onderzoek alleen in de achterstandswijken van Den Haag, waarbij een zeer sterke reductie van het aantal vragen is toegepast. Deze uitkomst ligt in lijn met andere onderzoeken waaruit blijkt dat het aantal mensen dat bereid is om een online vragenlijst in te vullen afneemt met het toenemen van de vragenlijstlengte; een meerderheid wil hieraan maxi- maal 10 minuten besteden [20, 23]. In Amsterdam en Almere leverde het inkorten van een gezondheidsvragenlijst van 20 naar 12 pagina's geen extra respons op, ondanks de vermelding in de aankondigingsbrief dat de invultijd 10 à 15 minuten was. Daarnaast leverde het inkorten voor online deelnemers ook relatief weinig tijdwinst op. Een mogelijke verklaring hiervoor is dat een langere vragenlijst leidt tot een kortere invulduur per vraag $[8,20]$. Ons onderzoek liet ook zien dat de meeste deelnemers uit Amsterdam en Almere ongeacht de lengte van de vragenlijst de online vragenlijsten afmaakten.

In de onderzoeksopzet in Den Haag zijn alleen inwoners uit achterstandswijken benaderd. In lijn met eerdere bevindingen dat de respons op de GM in ach- 
terstandswijken lager is dan gemiddeld [2, 4], is de respons op de lange vragenlijst in Den Haag lager dan in Almere en Amsterdam. Respondenten uit achterstandswijken in Den Haag die online deelnamen, haakten op de lange vragenlijst relatief vaak tussentijds af. De resultaten in Den Haag lieten onder 19- tot en met 34-jarigen en onder mannen een hogere respons zien op de themavragenlijsten dan op de lange vragenlijst. Dit betekent dat het sterk inkorten van een vragenlijst een antwoord kan zijn op de selectieve non-respons bij deze groepen zoals gezien bij de GM 2012 en 2016 [2, 3]. In Den Haag beschikten we niet over informatie over de migratieachtergrond van deelnemers. In Amsterdam deden inwoners van Nederlandse herkomst vaker mee aan de korte vragenlijst dan aan de lange vragenlijst. Amsterdammers van niet-Nederlandse herkomst vulden relatief vaak de Engelstalige korte vragenlijst in.

In dit onderzoek, net als in de GM 2016, vulde ongeveer twee derde van de respondenten de vragenlijst online in [3]. De lengte van de vragenlijst speelde binnen de drie onderzochte steden geen rol bij de manier van deelname. Het blijkt dat vooral inwoners met een migratieachtergrond tussen de 30 en 39 jaar een online vragenlijst op een smartphone invullen [31]. Dit kan mogelijk een verklaring zijn voor het hogere percentage deelnemers in Den Haag dat de vragenlijst op een smartphone invulde, in vergelijking met de andere twee steden. Daarnaast kan in Den Haag ook de lengte van de vragenlijst een rol hebben gespeeld bij het hogere percentage smartphonegebruikers; ongeveer een kwart van de deelnemers vulde de themavragenlijsten in met de smartphone. Immers, 10 minuten wordt voor de smartphone als optimale invultijd aangehouden [23].

Wij onderzochten in de achterstandswijken in Den Haag of de vragenlijst op B1-taalniveau een hogere respons zou opleveren dan de reguliere themavragenlijst. Dit bleek niet het geval, een uitkomst die afwijkt van de resultaten van eerdere onderzoeken, die aantoonden dat de respons op vragenlijsten hoger wordt als de vragen minder moeilijk zijn [9, 19]. In vergelijking met de lange vragenlijst lijken inwoners in Den Haag in de jongste leeftijdsgroep (19- tot en met 24jarigen) wel vaker op de B1-themavragenlijst te responderen, maar niet vaker op de reguliere themavragenlijst. Daarnaast zagen we onder deelnemers aan de B1-themavragenlijst vaker een verhoogd risico op een depressie en/of angststoornis, dan onder deelnemers aan de lange of de reguliere themavragenlijst. Een mogelijke verklaring is dat de respondenten de originele vragen te ingewikkeld vonden en daardoor hun klachten minder snel aangaven. Het is echter onduidelijk of de vragen op B1-taalniveau exact hetzelfde meten als de originele vragen. Validering van vereenvoudigde vragen is nodig voordat deze grootschalig ingezet worden.

Een sterk punt van dit onderzoek is dat de dataverzameling in de drie steden op dezelfde wijze is uitge- voerd als in de vierjaarlijkse landelijke GM, wat de bevindingen van dit onderzoek direct in de praktijk toepasbaar maken. Wel was het onderzoek kleinschaliger van opzet, en zijn alleen 19- tot en met 64-jarige inwoners uitgenodigd om deel te nemen. De groep 65plussers is niet meegenomen, omdat de respons onder 65-plussers op de GM doorgaans voldoende hoog is (50\% of hoger) [3].

Uiteraard kent het onderzoek ook enkele beperkingen. Zo konden de responseffecten naar migratieachtergrond alleen in Amsterdam en Almere in kaart worden gebracht. Verder was het oorspronkelijk de bedoeling om in elke stad gelijke groepen 19- tot en met 34-jarigen en 35- tot en met 64-jarigen uit te nodigen voor elke vragenlijstvariant. In de steekproeftrekking is in Almere en Den Haag met deze leeftijdsstratificatie onvoldoende rekening gehouden, zodat relatief meer mensen van 35 jaar of ouder een uitnodiging hebben ontvangen. In Amsterdam zijn abusievelijk geen lange vragenlijsten verstuurd naar 19- tot en met 24jarigen. In de analyses is hiermee rekening gehouden door voor leeftijd te corrigeren en de gegevens van 19tot en met 24-jarige Amsterdammers te excluderen.

Een andere beperking is het ontbreken van een Engelse versie in Den Haag voor deelnemers aan de B1themavragenlijst. Dit heeft de respons op de B1-themavragenlijst mogelijk iets verlaagd. Naar verwachting zouden ongeveer 13 deelnemers de vragenlijst in het Engels hebben ingevuld (het aantal Engelstalige deelnemers aan lang en thema was 13). Daarmee zou de respons op de Bl-themavragenlijst op 20,7\% uitkomen. Het verschil in respons met de themavragenlijst $(19,0 \%)$ is ook na deze correctie niet significant. Wanneer we voor het onderzoek naar de verschillen in gezondheidsuitkomsten de Engelstalige deelnemers op de lange en de themavragenlijst buiten beschouwing laten, blijft het gevonden verschil voor psychische klachten tussen B1-themavragenlijst en de lange vragenlijst bestaan.

Een vergelijking van de respons in dit onderzoek met die van de GM 2016, laat voor Almere geen verschillen zien [3]. Het responscijfer in Den Haag en Amsterdam kan niet vergeleken worden met de responscijfers uit 2016 vanwege methodeverschillen: in grote steden wordt normaliter bij het uitvoeren van de GM vier keer een aanschrijfbrief verstuurd en worden vertaalde brieven, vragenlijsten en mondelinge en/of telefonische interviews ingezet. In 2018 zijn deze extra inspanningen niet gedaan, met uitzondering van de online Engelse vertaling. Ook zijn in dit onderzoek in Den Haag alleen personen uit achterstandswijken benaderd.

\section{Conclusie}

Een zeer korte gezondheidsvragenlijst van 6 pagina's met een verwachte invulduur van 5 à 10 minuten heeft een positief effect op de respons, in elk geval onder inwoners van lage SES-wijken. Het advies aan GGD'en 
voor de vierjaarlijkse landelijke GM volwassenen en ouderen is dan ook om te onderzoeken op welke manier de vragenlijst aanzienlijk kan worden ingekort om de respons onder moeilijk bereikbare groepen te verhogen. Overwogen kan worden om de gezondheidsvragenlijst in modules aan te bieden of om jaarlijks een thematische gezondheidsmonitor uit te voeren. Hierbij dient ook onderzocht te worden wat het responsverhogende effect is bij zeer korte themavragenlijsten over gezondheidsthema's anders dan psychosociale gezondheid.

De resultaten in dit onderzoek wijzen er niet op dat een eenvoudiger taalniveau de respons bevordert. Ook hier geldt echter dat verder onderzoek naar de effecten van B1-taalniveau op de uitkomsten nodig is, ook bij andere gezondheidsthema's.

GGD'en staan enerzijds voor de opgave om voor de monitoring van gezondheid, een wettelijke taak, naar nieuwe oplossingen te zoeken voor de dalende en mogelijk selectieve respons. Anderzijds willen GGD'en deze waardevolle gezamenlijke dataverzameling ook behouden en trends in gezondheidsuitkomsten blijven volgen. Dit vormt een uitdaging in de huidige tijd van toenemende enquêtedruk en in een samenleving die door de digitalisering in sneltreinvaart verandert.

Open Access This article is licensed under a Creative Commons Attribution 4.0 International License, which permits use, sharing, adaptation, distribution and reproduction in any medium or format, as long as you give appropriate credit to the original author(s) and the source, provide a link to the Creative Commons licence, and indicate if changes were made. The images or other third party material in this article are included in the article's Creative Commons licence, unless indicated otherwise in a credit line to the material. If material is not included in the article's Creative Commons licence and your intended use is not permitted by statutory regulation or exceeds the permitted use, you will need to obtain permission directly from the copyright holder. To view a copy of this licence, visit http://creativecommons.org/licenses/by/4.0/.

\section{Literatuur}

1. Koninkrijk der Nederlanden. Wet van 9 oktober 2008, houdendebepalingen over dezorgvoor depubliekegezondheid (Wet publieke gezondheid). Staatsblad. 2008;460:1-23.

2. Brink CL van den, Herten MH van, Boeker S. Gezondheidsmonitor 2012. Tijdschr Gezondheidswet. 2017;95:222-7.

3. Terpstra J. Landelijke inventarisatie respons Gezondheidsmonitor volwassenen en ouderen 2016. Nijmegen: GGD GelderlandZuid; 2018.

4. GGD Haaglanden. Gezondheidsenquête Haaglanden 2016 1. Methode en respons. Den Haag: GGD Haaglanden; 2017.

5. Dijkshoorn H, Boom W van den. Opzet, dataverzameling en respons Amsterdamse Gezondheidsmonitor 2016. Amsterdam: GGD Amsterdam; 2018.

6. Guo Y, Kopec JA, Cibere J, et al. Population survey features and response rates: a randomized experiment. Am J Public Health. 2016;106:1422-6.

7. Rolstad S, Adler J, Rydén A. Response burden and questionnaire length: is shorter better? a review and meta-analyses. Value Health. 2011;14:1101-8.
8. Allen DS. The impact of shortening a long survey on response rate and response quality. Thesis and dissertation 5968. Provo: Brigham Young University; 2016.

9. Edwards PJ, Roberts I, Clarke MJ, et al. Methods to increase response to postal and electronic questionnaires. Cochrane Database Syst Rev. 2009; https://doi.org/10. 1002/14651858.MR000008.pub4.

10. Kenyon S, Pike K, Jones D, et al. The effect of a monetary incentive on return of a postal health and development questionnaire: a randomised trial. BMC Health Serv Res. 2005;5:55.

11. Robb KA, Gatting L, Wardle J. What impact do questionnaire length and monetary incentives have on mailed health psychology survey response? Br J Health Psychol. 2017;22:671-85.

12. Sahlqvist S, Song Y, Bull F, et al. Effect of questionnaire length, personalisation and reminder type on response rate to a complex postal survey: randomised controlled trial. BMCMed Res Methodol. 2011;11:62.

13. Gelder MMvan, Vlenterie R, IntHout J, et al. Most responseinducing strategies do not increase participation in observational studies: a systematic review and meta-analysis. JClin Epidemiol. 2018;99:1-13.

14. Heerwegh D, Loosveldt G. An experimental study on the effects of personalization, surveylength statements, progress indicators, and survey sponsor logos in Web Surveys. J Off Stat. 2006;22:191.

15. Jin L. Improving response rates in web surveys with default setting: the effects of default on web survey participation and permission. Int J Market Res. 2011;53:75-94.

16. Kaplowitz MD, Lupi F, Couper MP, et al. The effect of invitation design on web survey response rates. Soc Sci ComputRev. 2012;30:339-49.

17. Liu M, Wronski L. Examining completion rates in web surveys via over 25,000 real-world surveys. Soc Sci Comput Rev. 2018;36:116-24.

18. Mavletova A, Deviatko I, Maloshonok N. Invitation design elements in web surveys-can one ignore interactions? Bull Soc Methodol. 2014;123:68-79.

19. Yan T, Conrad F, Tourangeau R, et al. Should I stay or should I go: the effects of progressfeedback, promised taskduration, and length of questionnaire on completing web surveys. Int J Public Opin Res. 2010;23:131-47.

20. Galesic M, Bosnjak M. Effects of questionnaire length on participation and indicators of response quality in a web survey. Public Opin Quart. 2009;73:349-60.

21. Andringa W, Huijgen G. Smartphone wordt belangrijker bij dataverzameling. Amsterdam/Enschede: I\&O Research. 2018. https://www.ioresearch.nl/actueel/smartphonewordt-belangrijker-bij-dataverzameling. Geraadpleegd op: 1 jul 2019.

22. De Leeuw E, Toepoel V. Mixed-mode and mixed-device surveys. In: Vannette D, Krosnick J, redactie. The Palgrave handbook of survey research. Cham: Palgrave MacMillan; 2018. pag. 51-61.

23. Kelly F, Johnson A, Stevens S. Modular survey design: bite sized chunks 2. 2013. pag. 1. Geraadpleegd op 23 juli 2019.

24. Buisman M, Houtkoop W. Laaggeletterdheid in kaart. 's-Hertogenbosch: Expertisecentrum Beroepsonderwijs/ Stichting Lezen en Schrijven; 2014.

25. Paktaal. Taalniveaus. 2020. https://paktaal.nl/taalniveaus. Geraadpleegd op: 1 jul 2019.

26. Lempens A, Nordeman R, Zandvliet R. Hoe kunnen we laaggeletterden stimuleren om vaker mee te doen aan onderzoek? Amsterdam/Enschede: I\&O Research. 2017. https://ioresearch.nl/Home/Nieuws/hoe-kunnen- 
we-laaggeletterden-stimuleren-om-vaker-mee-te-doenaan-onderzoek. Geraadpleegd op: 23 jul 2019.

27. Gemeente Den Haag. Onderzoek Kloek Adviezen $S \& O$ en OCW/Onderzoek. Den Haag in Cijfers. Achterstandsscores 2017. 2017. https:// denhaag.incijfers.nl. Geraadpleegd op: 23 jul 2019.

28. Kessler RC, Barker PR, Colpe LJ, et al. Screening for serious mental illness in the general population. Arch Gen Psychiatry. 2003;60:184-9.
29. Jong-Gierveld J de, Kamphuis FH. The development of a Rasch-type loneliness-scale. Appl Psychol Meas. 1985;9:289-99.

30. Jong-Gierveld J de, Tilburg T van. Manual of the Loneliness Scale 1999. Amsterdam: Vrije Universiteit. 2017. https:// home.fsw.vu.nl/tg.van.tilburg/manual_loneliness_scale_ 1999.html. Geraadpleegd op: 23 jul 2019.

31. RobertsA. Theeffectofrespondent characteristicsonbreakoff in online surveys; a comparison between respondents using smartphones, tablets and pc. Heerlen: Centraal Bureau voor deStatistiek; 2017. 